\title{
Casein nanoparticles as carriers for the oral delivery of folic acid
}

\section{Authors}

Rebeca Penalva ${ }^{a}$, Irene Esparza ${ }^{a}$, Maite Agüeros ${ }^{a}$, Carlos J. Gonzalez-Navarro ${ }^{b}$, Carolina Gonzalez-Ferrero ${ }^{c}$, Juan M. Irache ${ }^{a}$

\section{Affiliation}

a Department of Pharmacy and Pharmaceutical Technology, University of Navarra, 31008 - Pamplona, Spain.

${ }^{\mathrm{b}}$ Centre for Nutrition Research, University of Navarra, 31080 - Pamplona, Spain.

c Centro Nacional de Tecnología y Seguridad Alimentaria - CNTA, San Adrián, Spain.

\section{Corresponding author:}

Prof. Juan M. Irache

Dep. Pharmacy and Pharmaceutical Technology

University of Navarra

$\mathrm{C} /$ Irunlarrea, 1

31080 - Pamplona

Spain

Phone: +34948425600

Fax: +34948425619

E-mail: jmirache@unav.es 


\begin{abstract}
Alimentary proteins can be viewed as an adequate material for the preparation of nanoparticles and microparticles. They offer several advantages such as their digestibility, price and a good capability to interact with a wide variety of compounds and nutrients. The aim of this work was to prepare and characterize casein nanoparticles for the oral delivery of folic acid. These nanoparticles were prepared by a coacervation process, stabilized with either lysine or arginine and, finally, dried by spray-drying. For some batches, the effect of a supplementary treatment of nanoparticles (before drying) with hydrodynamic high pressure on the properties of the resulting carriers was also evaluated. The resulting nanoparticles displayed a mean size close to $150 \mathrm{~nm}$ and a folic acid content of around $25 \mathrm{mg}$ per mg nanoparticle. From the in vitro release studies, it was observed that casein nanoparticles acted as gastro-resistant devices and, thus, folic acid was only released under simulated intestinal conditions. For the pharmacokinetic study, folic acid was orally administered to laboratory animals as a single dose of $1 \mathrm{mg} / \mathrm{kg}$. Animals treated with folic acidloaded casein nanoparticles displayed significantly higher serum levels than those observed in animals receiving an aqueous solution of the vitamin. As a consequence the oral bioavailability of folic acid when administered in casein nanoparticles was calculated to be around $52 \%$, a $50 \%$ higher than with the traditional aqueous solution. Unfortunately, the treatment of casein nanoparticles by hydrodynamic high pressure modified neither the release profile of the vitamin nor its oral bioavailability.
\end{abstract}

\title{
Key words
}

Casein, nanoparticles, folic acid, lysine, bioavailability, oral delivery 


\section{Introduction}

In recent years, nano- and microencapsulation has been a growing interest for pharmaceutical, nutraceutical and food applications. These techniques involve the trapping, surrounding or enveloping of compounds or ingredients within a secondary material and delivering them in small particles within the nanometer to micrometer range (Augustin, Sanguansri, \& Lockett, 2013; Kuang, Oliveira, \& Crean, 2010).

For food applications, these nano- and microencapsulation approaches may be of interest for any of the following reasons: i) protect the compound of interest from its premature degradation (during processing or storage) or undesirable interactions with the environment; ii) mask astringency tastes; iii) facilitate its processability (improving solubility and dispersability); iv) control and/or prolong its release; and/or v) improve its oral bioavailability (Desai \& Jin Park, 2005; Quintanilla-Carvajal et al., 2010).

On the other hand, there are a number of materials that may be potentially useful for designing encapsulated formulations. This versatility allows for the design of a number of delivery systems including micelles from surfactants and biopolymers (Esmaili et al., 2011; Garti, Spernath, Aserin, \& Lutz, 2005), nanoemulsions and liposomes from lipids (Reza Mozafari, Johnson, Hatziantoniou, \& Demetzos, 2008; Silva, Cerqueira, \& Vicente, 2012), polymeric nanoparticles and microparticles from polymers, macromolecules or lipids (Desai \& Jin Park, 2005; Ezhilarasi, Karthik, Chhanwal, \& Anandharamakrishnan, 2013; Weiss et al., 2008).

Alimentary proteins, naturally present in food, offer a great potential as a material for the preparation of nanoparticles and microparticles. Overall they are biodegradable, digestible, cheap, offer a nutritional value, and, due to the presence of a number of functional groups, they can interact with a wide variety of compounds in a relatively non-specific way. Another important point is that they are usually considered as GRAS (generally recognized as safe) compounds. In addition, the procedures to transform these proteins into nanoparticles or microparticles are simple and can be performed in an aqueous medium or in environmentally accepted solvents. Examples of these proteins include legumin and vicilin from peas (Pisum sativum L.) (Ezpeleta, Irache, Stainmesse, Gueguen, \& Orecchioni, 1996; Irache, Bergougnoux, Ezpeleta, Gueguen, \& Orecchioni, 1995), gliadin from wheat (Arangoa, Campanero, Renedo, Ponchel, \& Irache, 2001; Ezpeleta et al., 1996), zein from corn (Zhong, Tian, \& Zivanovic, 2009) or proteins from soy (Glycine max L.) (Teng, Luo, \& Wang, 2012).

Another interesting protein for micro- and nanoparticle design is casein. Casein is the major milk protein and possesses many structural and physicochemical properties that facilitate its functionality in drug delivery systems (Semo, Kesselman, Danino, \& Livney, 2007). Thus, casein-based devices have been proposed for delivering hydrophobic bioactives and drugs including vitamin D2 (Semo et al., 2007), thymol (Pan, Mu, Hu, Yao, \& Jiang, 2006), curcumin (Esmaili et al., 2011), and paclitaxel (Shapira, Davidson, Avni, Assaraf, \& Livney, 2012). 
Folic acid (pteroyl-L-glutamic acid, vitamin B9) is a water-soluble vitamin that is essential in the human diet. The naturally occurring form of folic acid, folate, is typically obtained through consumption of green vegetables or dietary supplements (Brouwer, van Dusseldorp, West, \& Steegers-Theunissen, 2001). This vitamin is especially important during the periods of rapid cell division and growth such as pregnancy and infancy when it is often necessary to take specific dosages of folic acid on daily basis (Lamers, 2011). The insufficiency of folic acid has long been known to be related to certain diseases such as neural tube defects in fetus and megaloblastic anaemia (Heseker, 2011). Other ailments associated with low levels of folic acid range from nervous system disturbances to cardiovascular disorders and cancer (lyer \& Tomar, 2009; Kolb \& Petrie, 2013). It is assumed that on a population level, nutritional requirements for folate cannot be completely covered by a varied diet, as recommended by national health authorities (Iyer \& Tomar, 2009). Thus, fortification with folic acid in one or more of the commonly consumed dietary items (i.e maize flour, milk, bread, etc) has been proposed as the best method to ensure that increased folate intake reduces the risks associated with folate deficiency. However, folic acid and folates are rather unstable molecules. In fact, folic acid is photosensitive and suffers from oxidative degradation, which is enhanced by oxygen, heat and acid $\mathrm{pH}$ conditions (Akhtar, Khan, \& Ahmad, 1999; Off et al., 2005). This results in a splitting of the molecule into biologically inactive forms (Madziva, Kailasapathy, \& Phillips, 2006) and, as suggested from different studies, in a significant decrease in the oral bioavailability of the vitamin (Ohrvik \& Witthoft, 2011; O'Leary \& Sheehy, 2001).

The aim of this work was to design casein nanoparticles for the oral delivery of folic acid. The encapsulation of this vitamin in these carriers may be of interest to minimize the adverse effects and deteriorative reactions induced during food processing and cooking as well as to improve the oral bioavailability. In order to evaluate the capability of casein nanoparticles to promote the oral bioavailability of folic acid, a pharmacokinetic study in laboratory animals was carried out.

\section{Materials and methods}

\subsection{Materials}

Sodium caseinate was obtained from ANVISA (Madrid, Spain). Folic acid, lysine, arginine, pepsin, pancreatin, manitol and sodium chloride were from Sigma-Aldrich (Germany) whereas ethanol and acetonitrile (HPLC grade) were from Merck (Darmstadt, Germany). AccuDiag ${ }^{\mathrm{TM}}$ Folate-Folic acid ELISA Kit was purchased from Diagnostic Automation/ Cortez Diagnostics Inc. (USA). All reagents and chemicals used were of analytical grade.

\subsection{Preparation of casein nanoparticles}

Casein nanoparticles were prepared by a coacervation procedure followed by a purification step by ultrafiltration and subsequent drying by Spray-drying. 


\subsubsection{Empty casein nanoparticles (NP)}

Briefly, $1 \mathrm{~g}$ sodium caseinate and a determined amount of a basic amino acid (either lysine or arginine) were firstly dissolved in $75 \mathrm{ml}$ purified water by magnetic agitation at room temperature. Then, nanoparticles were formed by the addition of $40 \mathrm{~mL}$ of a calcium chloride solution in purified water $(0.8 \% \mathrm{w} / \mathrm{v})$. The suspension was purified by ultrafiltration through a polysulfone membrane cartridge of $50 \mathrm{kDa}$ pore size (Medica SPA, Italy). Finally, $20 \mathrm{ml}$ of an aqueous solution of manitol $(100 \mathrm{mg} / \mathrm{ml})$ was added to the suspension of casein nanoparticles and the suspension was dried in a Büchi Mini Spray Drier B-290 apparatus (Büchi Labortechnik AG, Switzerland) under the following experimental conditions: (i) inlet temperature of $90 \circ \mathrm{C}$, (ii) outlet temperature $45-50^{\circ} \mathrm{C}$, (iii) air pressure: $2-5$ bar, (iv) pumping rate of $2-6 \mathrm{~mL} / \mathrm{min},(\mathrm{v})$ aspirator of $100 \%$ and (vi) air flow at $900 \mathrm{~L} / \mathrm{h}$.

\subsubsection{Folic acid-loaded casein nanoparticles (F-NP)}

The preparation of casein nanoparticles loaded with folic acid was similar to that of the empty particles, however some minor adjustments were employed. Thus, $1 \mathrm{~g}$ sodium caseinate and $50 \mathrm{mg}$ lysine were dissolved in $75 \mathrm{~mL}$ purified water. In parallel, $300 \mathrm{mg}$ folic acid was dissolved in an aqueous solution of lysine $(8 \mathrm{mg} / \mathrm{ml})$. Then, $9 \mathrm{ml}$ of the aqueous folic acid solution was added to the caseinate solution and the resulting mixture was incubated at room temperature for $10 \mathrm{~min}$ under magnetic agitation. Casein nanoparticles were obtained by the addition of $40 \mathrm{~mL}$ of a calcium chloride solution in water $(0.8 \% \mathrm{w} / \mathrm{v})$. The suspension was purified and dried as described above.

In order to evaluate the effect of a high pressure treatment on the main properties of these nanoparticles, some batches were subjected to different cycles of high hydrostatic pressure in an ISO-LAB FPG11500 apparatus (Stansted Fluid Power Ltd, UK) prior to the drying step.

For the identification of the different formulations, the following abbreviations were used: FA-NP-C (casein nanoparticles containing folic acid), FA-NP-C-Px (folic acid-loaded casein nanoparticles stabilized by high pressure) and NP-C (control casein nanoparticles).

\subsection{Characterization of nanoparticles}

\subsubsection{Size, zeta potential and morphology}

The mean hydrodynamic diameter and the zeta potential of nanoparticles was determined by photon correlation spectroscopy (PCS) and electrophoretic laser Doppler anemometry, respectively, using a Zetaplus apparatus (Brookhaven Instrument Corporation, USA). The diameter of the nanoparticles was determined after dispersion in ultrapure water $(1: 10)$ and measured at $25^{\circ} \mathrm{C}$ with a scattering angle 
of $90^{\circ} \mathrm{C}$. The zeta potential was measured after dispersion of the dried nanoparticles in $0.1 \mathrm{mM} \mathrm{KCl}$ solution.

The morphology and shape of nanoparticles was examined using a field emission scanning electron microscope FE-SEM (ULTRA Plus, Zeiss, The Netherlands). Prior to analysis, particles were washed to remove manitol. For this purpose, spray-dried nanoparticles were resuspended in ultrapure water and centrifuged at 27,000xg for 10 min. Then, the supernatants were discarded and the obtained pellets were mounted on copper grids. Finally, the pellet was shaded with an amalgam of gold/palladium during fifteen seconds using a sputter coater (K550X Emitech, Ashford, UK).

\subsubsection{Yield of the preparative process}

In order to quantify the amount of protein transformed into nanoparticles, a specific amount of the nanoparticle formulation was dispersed in water and centrifuged at $17,000 \times \mathrm{g}$ for $20 \mathrm{~min}$. Supernatants were discarded and the pellets were digested with $\mathrm{NaOH} 0.05 \mathrm{M}$ (casein nanoparticles). Then, the amount of protein was quantified by UV spectrophotometry at $282 \mathrm{~nm}$ in an Agilent 8453 system (Agilent Technologies, USA). For analysis, calibration curves were constructed between 150 and $1500 \mu \mathrm{g} / \mathrm{mL}\left(r^{2}>\right.$ 0.9992; quantitation limit $=119 \mu \mathrm{g} / \mathrm{mL}$ ).

The amount of protein forming nanoparticles in the formulation was estimated as the ratio between the amount of the protein quantified in the pellet of the centrifuged samples and the total amount of protein used for the preparation of nanoparticles and expressed as follows:

Yield $(\%)=($ Protein in pellet $) /($ Total protein in the formulation $) \times 100$ 1]

\subsubsection{Folic acid analysis}

The amount of folic acid loaded into the nanoparticles was quantified by HPLC-UV following an analytical method previously published by Sierra and collaborators (Sierra \& Vidal-Valverde, 1997) however with minor modifications. Analysis was carried out in an Agilent model 1100 series LC and a diode-array detector set at $290 \mathrm{~nm}$. The chromatographic system was equipped with a reversed-phase $150 \mathrm{~mm} \times 2.1 \mathrm{~mm}$ C18 Alltima column (particle size $5 \mu \mathrm{m}$; Altech, USA) and a Gemini C18 precolumn (particle size $5 \mu \mathrm{m}$; Phenomenex, CA, USA). The mobile phase, pumped at $0.25 \mathrm{~mL} / \mathrm{min}$, was a mixture of phosphoric acid $(33 \mathrm{mM}, \mathrm{pH} 2.3)$ and acetonitrile in a gradient condition (Table 1). The column was placed at $40^{\circ} \mathrm{C}$ and the injection volume was $10 \mu \mathrm{L}$. Under these conditions, folic acid eluted at $21.2 \pm 0.5 \mathrm{~min}$. For calculations, calibration curves were designed over the range of 2 and $200 \mu \mathrm{g} / \mathrm{mL}\left(r^{2}>0.999\right)$. The limit of quantitation was calculated to be $4.3 \mu \mathrm{g} / \mathrm{mL}$. 
For analysis, $10 \mathrm{mg}$ nanoparticles were dispersed in $1 \mathrm{~mL}$ water and centrifuged. The supernatants were analysed in order to determine the amount of free folic acid (non encapsulated. In order to determine the amount of folic acid loaded inside the nanoparticles, the pellets were digested with $\mathrm{NaOH} 0.05 \mathrm{M}$. In parallel, the total amount of folic acid in the dry formulations was quantified by direct digestion with $\mathrm{NaOH} 0.05 \mathrm{M}$. For this purpose $10 \mathrm{mg}$ of formulation was digested for $5 \mathrm{~min}$ in $1 \mathrm{~mL}$ of sodium hydroxide $0.05 \mathrm{M}$. In all cases the samples were filtered and transferred to auto-sampler vials, capped and placed in the HPLC auto-sampler. Each sample was assayed in triplicate and results were expressed as follows:

Folic acid loading $(\mu \mathrm{g} / \mathrm{mg}$ nanoparticles $)=(F A p+F A s) / W p$

Encapsulation efficiency (\%) $=$ FAp $\times 100 /$ Fat

[Eq. 3]

in which FAp and Fas corresponds to the amount of folic acid quantified in the pellets and supernatants, respectively; FAt is the total amount of folic acid in the dry formulation and $\mathrm{Wp}$ being the amount of protein quantified as described in section 2.3.2).

\subsection{In vitro release study}

Release experiments were conducted under sink conditions at $37^{\circ} \mathrm{C}$ using simulated gastric (SGF; pH 1.2; pepsin $0.32 \% \mathrm{w} / \mathrm{v}$ ) and intestinal (SIF; pH 6.8; pancreatin $1 \% \mathrm{w} / \mathrm{v}$ ) fluids. The studies were performed under agitation in a Vortemp 56TM Shaking Incubator (Labnet International Inc., NJ USA) after the dispersion of the nanoparticles in the appropriate medium.

For each specific each time interval, $20 \mu \mathrm{g}$ of folic acid formulated in nanoparticles was resuspended in $1 \mathrm{ml}$ of the corresponding simulated fluid. The different formulations were kept in the SGF for 2 hours before being transferred to SIF for a subsequent 20 hours. At different intervals, samples were collected and centrifuged at $17,000 \mathrm{rpm}$ for 20 minutes. The amount of folic acid released was quantified by HPLC from the supernatants.

\subsection{In vivo pharmacokinetic studies in male Wistar rats}

\subsubsection{Pharmacokinetic studies}

Pharmacokinetic studies were performed in male Wistar rats (200-250 g) obtained from Harlan (Barcelona, Spain). Studies were approved by the Ethical Committee for Animal Experimentation of the University of Navarra (protocol number 014-10) in accordance with the European legislation on animal experiments. Prior to the experiment, animals were adaptively fed for 1 week with free access to a Folic Acid deficient diet (TD 95247, Harlan, USA) and drinking water $\left(22 \pm 2^{\circ} \mathrm{C} ; 12\right.$-h light and $12-\mathrm{h}$ dark cycles; $50-60 \%$ relative humidity). Previous to the oral administration of the 
formulations, animals were fasted overnight to avoid interference with the absorption, allowing free access to water.

For the pharmacokinetic study, rats were randomly divided into 5 groups of 6 animals each. The experimental groups were: (i) aqueous solution of folic acid [Folic acid dissolved in PBS], (ii) folic acid-loaded casein nanoparticles (FA-NP-C) and (iii) folic acidloaded casein nanoparticles treated by high pressure (400 MPa, $5 \mathrm{~min}$ ) (FA-NP-C-P3). For controls, a group of animals were treated with a solution of folic acid in PBS intravenously administered and the last group of rats group received PBS (without folic acid) orally. Each animal received a folic acid dose of $1 \mathrm{mg} / \mathrm{kg}$ body weight either orally with a blunt needle via the oesophagus into the stomach or intravenously via tail vein. Blood samples were collected at different times post-administration in specific serum tubes (SARSTEDT Microtube $1,1 \mathrm{~mL}$ Z-Gel). The volemia was recovered intraperitoneally with an equal volume of sterile saline solution pre-heated to body temperature. Samples were immediately centrifuged at 10,000 rpm for $10 \mathrm{~min}$. Serum

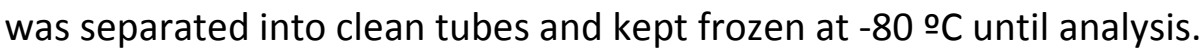

\subsubsection{Determination of Folic Acid in serum}

The amount of folic acid in serum was determined by an Enzyme Immunoassay. Calibrator and quality control samples were prepared by adding appropriate volumes of standard folic acid solution in PBS to serum. Calibration curves were designed over the range $4-450 \mathrm{ng} / \mathrm{mL}\left(r^{2}>0.996\right)$. For analysis, $100 \mu \mathrm{L}$ of the serum samples were added to each well of the microtiter plate, followed by the addition of $50 \mu \mathrm{L}$ of folic acid antibody. After incubation for $60 \mathrm{~min}$ at room temperature, the plate was washed three times with the washing solution (PBS-Tween $200.5 \%$ ). Then, $100 \mu \mathrm{L}$ of conjugate (anti-mouse-IgG-HRP) was added into each well and after $60 \mathrm{~min}$ at room temperature, the plate was washed again for three times with the washing solution. For the reaction, $100 \mu \mathrm{L}$ of substrate was added into each well and incubated in the dark for $20 \mathrm{~min}$ at room temperature. The reaction was stopped by the addition of 100 $\mu \mathrm{L}$ sulphuric acid $0.5 \mathrm{M}$ into each well. Finally, the absorbance was measured at 450 $\mathrm{nm}$ in a ELISA reader (Labsystems iEMS Reader MF).

Under these experimental conditions, the limit of quantification of this method was calculated to be $4 \mathrm{ng} / \mathrm{mL}$. The recovery of folic acid from serum samples was $90.1 \pm 0.3$ $\%$. Accuracy values during the same day (intraday assay) at low, medium and high concentrations of FA were always within the acceptable limits (less than 15\%).

\subsubsection{Pharmacokinetic data analysis}

The pharmacokinetic analysis of serum concentration plotted against time data, obtained after administration of the different folic acid formulations, was performed using a non-compartmental model with the WinNonlin 5.2 software (Pharsight Corporation, Mountain View, USA). The following parameters were estimated: maximal serum concentration $\left(C_{\max }\right)$, time taken to reach $C_{\max }\left(T_{\max }\right)$, area under the 
concentration-time curve from time 0 to $\infty$ (AUC), mean residence time (MRT), clearance $(\mathrm{Cl})$, volume of distribution $(\mathrm{V})$ and half-life in the terminal phase (t1/2). Furthermore, the relative oral bioavailability ( $\mathrm{Fr} \%$ ) of folic acid was estimated using the following equation:

$\operatorname{Fr}(\%)=A U C$ oral $/ A U C$ iv $\times 100 \quad$ [Eq. 4]

where AUC iv and AUC oral are the areas under the curve for the iv and oral administrations, respectively.

\subsection{Statistical analysis}

Data are expressed as the mean \pm standard deviation (S.D.) of at least three experiments. The non-parametric Kruskall-Wallis followed by Mann-Whitney U-test was used to investigate statistical differences. In all cases, $p<0.05$ was considered to be statistically significant. All data processing was performed using SPSS $^{\circledR}{ }^{\text {statistical }}$ software (SPSS ${ }^{\circledR} 15$, Microsoft, USA).

\section{Results}

\subsection{Optimization of the preparative process of casein nanoparticles}

Casein nanoparticles were prepared by coacervation in the presence of calcium. However, the resulting nanoparticles displayed a low stability in an aqueous environment. Thus, the first step of this work was to optimize the preparative process of casein nanoparticles in order to stabilize them by preventing their aggregation that occurs with time in an aqueous environment. For this purpose, the influence of the presence of either lysine or arginine on the physico-chemical properties and stability of the resulting nanoparticles was carried out. Table 2 summarizes the physico-chemical properties of casein nanoparticles when prepared at an amino acid/protein ratio of 0.12. Interestingly, when nanoparticles were prepared in the presence of a basic amino acid, the mean diameter of the resulting nanoparticles decreased significantly. Similarly, the polydispersity index was also slightly lower than for nanoparticles prepared in the absence of the amino acid. In all cases, the yield of the preparative process was high, with more than $95 \%$ of the initial protein transformed into nanoparticles.

On the other hand, the stabilizing effect of both lysine and arginine was found to be adequate with an amino acid/protein ratio ranged from 0.02 to 0.25 (data not shown). Regarding the stability of these nanoparticles in an aqueous medium, it was observed that for non-stabilised nanoparticles (NP-1 in Table 2) the mean size and the polydispersity index increased rapidly with time. In fact, two hours of incubation in water produced nanoparticles with a mean size close to $330 \mathrm{~nm}$ and a PDI of about 0.5. On the contrary, the size of nanoparticles stabilised with lysine were not affected for at 
least $48 \mathrm{~h}$, whereas nanoparticles stabilised with arginine displayed a similar size and PDI for $16 \mathrm{~h}$.

After purification of nanoparticles, the last step was to dry the suspensions in a Spraydrier apparatus. Here, again, the presence of the basic amino acid was a key factor to minimise the aggregation phenomenon between casein nanoparticles and the stability of the resulting nanoparticles (Table 3). In fact, for stabilised nanoparticles the mean size slightly increased (in comparison to fresh suspensions before the drying step, see Table 2); although, in all cases, the mean size of the resulting nanoparticles remained below $200 \mathrm{~nm}$. On the contrary, for unstabilised nanoparticles (NP-1), the mean size after drying increased significantly up until a size reaching around $300 \mathrm{~nm}$.

\subsection{Folic-acid loaded casein nanoparticles}

Table 4 summarizes the main physico-chemical properties of folic acid loaded nanoparticles. When the vitamin was encapsulated into casein nanoparticles, a moderate decrease in the mean size of the resulting carriers was observed (about 170 $\mathrm{nm}$ for empty nanoparticles vs $157 \mathrm{~nm}$ for FA-NP-C). Similarly, the negative zeta potential of nanoparticles slightly increased to $-17 \mathrm{mV}$. The folic acid loading into the casein nanoparticles (FA-NP-C) was calculated to be around $25 \mu \mathrm{g} / \mathrm{mg}$ nanoparticle with encapsulation efficiency of about $40 \%$.

In order to study the effect of a high hydrodynamic pressure treatment on the physicochemical characteristics of nanoparticles, different batches were subjected to increasing pressure conditions (from 100 to $600 \mathrm{MPa}$ ) for a period of $5 \mathrm{~min}$. Table 4 summarises these results. High pressure processing slightly decreased the mean size and the negative zeta potential of the resulting nanoparticles. On the contrary, the folic acid loading was not affected by a pressure treatment below $400 \mathrm{MPa}$. Under more drastic conditions (600 MPa for $5 \mathrm{~min}$ ) the folic acid loading appeared to increase; although this result can be related to a decrease in the recovery of small nanoparticles by centrifugation (see Methods).

Figure 1 shows the SEM microphotographs of folic acid-loaded casein nanoparticles. Nanoparticles prepared without using the high pressure treatment appear to be spherical. However, the same nanoparticles displayed an irregular shape with a rough surface following treatment with hydrodynamic high pressure. In any case, the apparent sizes observed by SEM were similar to those obtained values by photon correlation spectroscopy.

\subsection{In vitro release study}

Folic acid release kinetics from casein nanoparticles were evaluated in two different media: simulated gastric fluid (SGF) and simulated intestinal fluid (SIF). Figure 2 represents the release profiles of folic acid from the different assayed formulations as cumulative percentage of drug released as a function of time. 
For all the formulations evaluated, there was no release of folic acid when nanoparticles were dispersed in SGF. In contrast, when nanoparticles were dispersed in the SIF, the release behavior of folic acid from the nanoparticles exhibited a biphasic pattern. For conventional casein nanoparticles (FA-NP-C), an extremely rapid discharge of folic acid (close to $60-70 \%$ of the loaded vitamin) was exhibited followed by a more sustained and slow release of the vitamin. Finally, around $90 \%$ of the loaded vitamin was released. For the formulations of casein nanoparticles stabilized by high pressure (FA-NP- $\mathrm{C}_{3}$ ), again, the first pulse of folic acid release was also around $60-70 \%$; although after this stage, no further release was displayed for at least 7 hours.

\subsection{Pharmacokinetic studies in Wistar rats}

The serum concentration profiles for the folic acid solution in PBS after a single intravenous injection (dose $1 \mathrm{mg} / \mathrm{kg}$ ) are presented in Figure 3. Data were adjusted to a non-compartmental model. The folic acid serum concentration decreased rapidly displaying a biphasic pattern. The peak plasma concentration $\left(C_{\max }\right)$ of folic acid was about $6 \mu \mathrm{g} / \mathrm{mL}$. The values obtained for AUC and half-life $\left(t_{1 / 2}\right)$ were $3.7 \mu \mathrm{g} \mathrm{h} / \mathrm{mL}$ and 1.1 hours, respectively. The mean residence time (MRT) was 0.9 hours; whereas the folic acid clearance and its volume of distribution were calculated to be $0.06 \mathrm{~L} / \mathrm{h}$ and $0.1 \mathrm{~L}$, respectively (Table 5).

Figure 4 shows the serum concentration versus time profile after oral administration of folic acid (single dose of $1 \mathrm{mg} / \mathrm{kg}$ ) formulated as aqueous solution or loaded in casein nanoparticles. From the oral administration of the aqueous solution, the folic acid levels in the serum of animals increased rapidly during the first 1 hour postadministration (in which the $C_{\max }$ was reached). Then, the amount of vitamin in serum decreased slowly until the end of the experiment ( $24 \mathrm{~h}$ post-administration). For nanoparticle formulations, the folic acid serum levels vs. time displayed similar profiles to the one obtained for the free folic acid (FA solution). However, in all cases, the serum levels of the vitamin from nanoparticles were significantly higher than these observed for the aqueous solution of folic acid. Surprisingly, the treatment of casein nanoparticles by high hydrodynamic pressure did not significantly modify the serum vitamin levels observed with untreated nanoparticles.

Table 5 summarizes the pharmacokinetic parameters estimated for the analysis of the experimental data obtained after the administration of the different folic acid formulations to rats. When folic acid was administrated as aqueous solution, the AUC was around $1.4 \mu \mathrm{g} \mathrm{h} / \mathrm{mL}$. In the case of folic acid encapsulated in casein nanoparticles, the AUC was around $2.0 \mu \mathrm{g} \mathrm{h} / \mathrm{mL}$ and a similar value was observed when the nanoparticles were treated with high pressure $(2.2 \mu \mathrm{g} \mathrm{h} / \mathrm{mL})$. In any case, the AUC values of nanoparticles were significantly higher than those of orally administered free folic acid $(p<0.05)$. Similarly, the peak plasma concentration $\left(C_{\max }\right)$ of folic acid in the nanoparticles was around 1.5- times higher than for the aqueous solution of the vitamin. On the contrary, other important pharmacokinetic parameters of folic (eg. 
volume of distribution, clearance or half-life of the terminal phase) were statistically similar when the vitamin was administered as aqueous solution or loaded in casein nanoparticles $(p<0.05)$. Finally, the relative oral bioavailability of folic acid when incorporated to casein nanoparticles was of about $52 \%$, whereas for the folic acid aqueous solution the oral bioavailability was only of $35 \%$.

\section{Discussion}

Casein proteins ( $\alpha$ s1, as2, $\beta$, and $\mathrm{k}$ ) exist in milk under a "micellar" form whilst displaying the appearance of spherical aggregates of around 50 to $500 \mathrm{~nm}$ and have also been considered as a natural nano-delivery system (Udabage, McKinnon, \& Augustin, 2003; Walstra, 1999). In spite of their interest, only recently have caseinbased nanovehicles been successfully harnessed and stabilized with adequate procedures for delivering bioactives and drugs. In this context, three main approaches can be applied. The first one is based on the copolymerization of casein with synthetic polymers such as acrylic acid (Zhen, Wang, Xie, Wu, \& Jiang, 2013) or dextran (Pan et al., 2006). The second one is based on the formation of nanoparticles via electrostatic complexation between the protein and polysaccharides, including Arabic gum (Ye, Flanagan, \& Singh, 2006) or chitosan (Anal, Tobiassen, Flanagan, \& Singh, 2008). Finally, the last procedure and arguably the most popular, consists of a hardening step or cross-linking process of the newly formed casein nanoparticles. Amongst others, this stabilization of casein nanoparticles can be obtained by thermal treatment (Zimet, Rosenberg, \& Livney, 2011) or enzymatic cross-linkage with genipin (Elzoghby, Helmy, Samy, \& Elgindy, 2013) or transglutaminase (Huppertz \& de Kruif, 2008).

In this work we describe the preparation of casein nanoparticles under mild conditions in an aqueous environment using a basic amino acid (eg. lysine or arginine) as a stabilizing agent of the resulting nanocarriers. These nanoparticles were subsequently dried using a Spray-drying apparatus. The stabilization of casein nanoparticles using either lysine or arginine offered two main technological advantages. Firstly, the addition of basic amino acids prevented the aggregation of casein nanoparticles when dispersed in an aqueous medium. In the case of nanoparticles stabilized with lysine, there was no variation in the physico-chemical properties of these nanoparticles $48 \mathrm{~h}$ after their incubation in an aqueous medium. Secondly, the presence of the basic amino acid also minimized the physical interaction between nanoparticles during the drying step. Thus for nanoparticles stabilized with either lysine or arginine the drying step induced an increase of around $30 \%$ in the mean size of freshly prepared nanoparticles. For unstabilized nanoparticles, the mean size after the drying step was found to be about 2 times higher than before drying.

Casein nanoparticles were evaluated as oral delivery systems for folic acid. The use of casein offers an important advantage due to its capability to bind, through hydrophobic bonds, with vitamin B9 thus protecting the folic acid against 
photodecomposition (Zhang et al., 2014). The resulting folic acid-loaded nanoparticles were spherical (Figure 1) and displayed a size of around $157 \mathrm{~nm}$ with a vitamin loading of about $25 \mu \mathrm{g}$ per mg nanoparticle (Table 3). Some batches of casein nanoparticles were treated with high hydrodynamic pressure in order to harden them, thus to modify and modulate the release rate and the bioavailability of folic acid. Following an ultra-high pressure homogenization process the average diameter of folic acid-loaded casein nanoparticles decreased. Thus, at $400 \mathrm{MPa}$ for $5 \mathrm{~min}$, the mean size of nanoparticles was $15 \%$ lower than with untreated nanoparticles. This finding is consistent with those of Semo and co-workers who found a decrease in the average diameter of $\beta$-casein micelles treated by ultra-high pressure homogenization (Semo et al., 2007). In our case, the high pressure treatment also resulted in a morphology change of the resulting nanoparticles, which displayed an irregular shape as observed by SEM (Figure 1).

The release profile of folic acid from casein nanoparticles was found to be dependent on the $\mathrm{pH}$ conditions (Figure 2). Thus, under simulated gastric conditions ( $\mathrm{pH} \mathrm{1.2),} \mathrm{no}$ vitamin release was observed from the casein nanoparticles. This effect could be due to the fact that pepsin preferably attacks peptide bonds involving hydrophobic aromatic amino acids. These residues, due to their hydrophobicity, would be trapped inside the protein network during the preparation of casein nanoparticles by the addition of calcium chloride (Beaulieu, Savoie, Paquin, \& Subirade, 2002). On the contrary, under simulated intestinal conditions, the folic acid release profile was firstly characterised by a rapid release of the cargo followed by a more continuous and slower unloading of the remaining folic acid. This phenomenon can be related with the repulsion effect between the negative charges of both folic acid and casein at a neutral $\mathrm{pH}$. In fact, casein is a phosphoprotein with an apparent isoelectric point of 4.6 (Holt, 1992) and therefore, at $\mathrm{pH} \mathrm{6.8,} \mathrm{both} \mathrm{casein} \mathrm{and} \mathrm{folic} \mathrm{acid} \mathrm{should} \mathrm{present} \mathrm{a} \mathrm{net} \mathrm{negative}$ charge that would eject the vitamin from the carrier. On the other hand, the treatment of casein nanoparticles with a high pressure procedure had little effect on the release profile of folic acid. The main difference was that, at intestinal $\mathrm{pH}$, the folic acid release was around $10 \%$ lower than that observed with untreated casein nanoparticles.

For the in vivo pharmacokinetic studies, a single dose of $1 \mathrm{mg} / \mathrm{kg}$ of folic acid was selected. When folic acid was administered orally, either as aqueous solution or loaded in casein nanoparticles, the serum levels of the vitamin increased rapidly and the maximum plasma concentrations were achieved within a very short time period, ie. within $1.5 \mathrm{~h}$ post-administration. Following this, the folic acid levels declined slowly and were quantified in serum up to $24 \mathrm{~h}$ post administration. Interestingly, these profiles of folic acid serum concentration vs time were similar to those reported previously by other authors, in which human studies were used (Alemdaroglu, Dietz, Wolffram, Spahn-Langguth, \& Langguth, 2008; Nguyen et al., 2008). In any case, folic acid serum levels and AUC from casein nanoparticles were significantly higher than those observed with the traditional aqueous solution (Table 4). With the different 
formulations tested, the rank order of the mean AUC of serum folic acid concentration vs time was as follows: FA-NP-C- $P_{3}=$ FA-NP-C $>$ FA solution $(p<0.05)$. In accordance to this, the relative oral bioavailability (calculated as the ratio between the AUC of folic acid when administered orally and the AUC of the intravenous solution) was calculated to be $35 \%$ for the aqueous solution and $52 \%$ for casein nanoparticles. The treatment of casein nanoparticles by high pressure (400 MPa) had not significant effect on this pharmacokinetic parameter.

The values obtained from the pharmacokinetic bioavailability study are not easily comparable with previous results due to a scarcity of this information in the literature. In addition some factors such as the interindividual variation, the diet and the dose may produce different results (Brouwer et al., 2001). In this context, in a recent study, Nguyen et al. compared the serum levels of a single dose of folic acid in non-pregnant women. At low doses of the vitamin $(20$ and $70 \mu \mathrm{g} / \mathrm{kg}$ ) they stated that a proportional relationship between folic acid dosing and pharmacokinetics (AUC) exists (Nguyen et al., 2008). On the contrary, another interesting work in which folic acid was evaluated in healthy volunteers at a single dose of either 0.6 or $3 \mathrm{mg} / \mathrm{kg}$, the oral bioavailability of the vitamin appeared to be highly influenced by the dose. Thus, with the lower dose, the bioavailability was particularly high (around 60\%); differently, with the higher dose tested, this parameter was only around 17\% (Schmitz, Stuart, \& Priest, 1994). This observation could be related to the fact that, at least in part, intestinal absorption of folic acid through the small intestine is a saturable process (Mason, Shoda, Haskell, Selhub, \& Rosenberg, 1990; Russell et al., 1988).

\section{Conclusions}

In summary, casein nanoparticles can be prepared by coacervation with calcium and subsequently dried in a Spray-drying apparatus. The use of either lysine or arginine allows for a successful stabilisation of the resulting nanoparticles, preventing their aggregation in an aqueous environment. In this way, casein nanoparticles were capable of encapsulating folic acid, preventing its release in an acid environment and thus promoting its oral bioavailability, as observed during studies using a rat model. Unfortunately, under the experimental conditions used in this work, the treatment of casein nanoparticles with a high hydrodynamic pressure did not significantly modify the release profile and oral bioavailability of folic acid. In any case, the oral bioavailability of folic acid when administered in casein nanoparticles was around $50 \%$ higher than when formulated as an aqueous solution.

\section{Acknowledgements}

This work was supported by the Regional Government of Navarra (Alimentos funcionales, Euroinnova call) and the Spanish Ministry of Science and Innovation 
(ADICAP; ref. IPT-2011-1717-900000). Rebeca Penalva acknowledges the "Asociación de Amigos Universidad de Navarra" for the financial support.

\section{References}

Akhtar, M. J., Khan, M. A., \& Ahmad, I. (1999). Photodegradation of folic acid in aqueous solution. Journal of Pharmaceutical and Biomedical Analysis, 19(3), 269275.

Alemdaroglu, N. C., Dietz, U., Wolffram, S., Spahn-Langguth, H., \& Langguth, P. (2008). Influence of green and black tea on folic acid pharmacokinetics in healthy volunteers: Potential risk of diminished folic acid bioavailability. Biopharmaceutics \& Drug Disposition, 29(6), 335-348.

Anal, A. K., Tobiassen, A., Flanagan, J., \& Singh, H. (2008). Preparation and characterization of nanoparticles formed by chitosan-caseinate interactions. Colloids and Surfaces B: Biointerfaces, 64(1), 104-110.

Arangoa, M. A., Campanero, M. A., Renedo, M. J., Ponchel, G., \& Irache, J. M. (2001). Gliadin nanoparticles as carriers for the oral administration of lipophilic drugs. relationships between bioadhesion and pharmacokinetics. Pharmaceutical Research, 18(11), 1521-1527.

Augustin, M. A., Sanguansri, L., \& Lockett, T. (2013). Nano-and micro-encapsulated systems for enhancing the delivery of resveratrol. Annals of the New York Academy of Sciences, 1290(1), 107-112.

Beaulieu, L., Savoie, L., Paquin, P., \& Subirade, M. (2002). Elaboration and characterization of whey protein beads by an emulsification/cold gelation process: Application for the protection of retinol. Biomacromolecules, 3(2), 239-248.

Brouwer, I. A., van Dusseldorp, M., West, C. E., \& Steegers-Theunissen, R. P. (2001). Bioavailability and bioefficacy of folate and folic acid in man. Nutrition Research Reviews, 14(02), 267-294.

Desai, K. G. H., \& Jin Park, H. (2005). Recent developments in microencapsulation of food ingredients. Drying Technology, 23(7), 1361-1394.

Elzoghby, A. O., Helmy, M. W., Samy, W. M., \& Elgindy, N. A. (2013). Spray-dried casein-based micelles as a vehicle for solubilization and controlled delivery of flutamide: Formulation, characterization, and in vivo pharmacokinetics. European Journal of Pharmaceutics and Biopharmaceutics, 84(3), 487-496.

Esmaili, M., Ghaffari, S. M., Moosavi-Movahedi, Z., Atri, M. S., Sharifizadeh, A., Farhadi, M., .. Moosavi-Movahedi, A. A. (2011). Beta casein-micelle as a nano vehicle for solubility enhancement of curcumin; food industry application. LWT-Food Science and Technology, 44(10), 2166-2172.

Ezhilarasi, P., Karthik, P., Chhanwal, N., \& Anandharamakrishnan, C. (2013). Nanoencapsulation techniques for food bioactive components: A review. Food and Bioprocess Technology, 6(3), 628-647. 
Ezpeleta, I., Irache, J. M., Stainmesse, S., Gueguen, J., \& Orecchioni, A. (1996). Preparation of small-sized particles from vicilin (vegetal protein from Pisum sativum L.) by coacervation. European Journal of Pharmaceutics and Biopharmaceutics, 42(1), 36-41.

Garti, N., Spernath, A., Aserin, A., \& Lutz, R. (2005). Nano-sized self-assemblies of nonionic surfactants as solubilization reservoirs and microreactors for food systems. Soft Matter, 1(3), 206-218.

Heseker, H. (2011). Folic acid and other potential measures in the prevention of neural tube defects. Annals of Nutrition \& Metabolism, 59(1), 41-45.

Holt, C. (1992). Structure and stability of bovine casein micelles. Advances in protein chemistry (pp. 63-151) Academic Press.

Huppertz, T., \& de Kruif, C. G. (2008). Structure and stability of nanogel particles prepared by internal cross-linking of casein micelles. International Dairy Journal, 18(5), 556-565.

Irache, J. M., Bergougnoux, L., Ezpeleta, I., Gueguen, J., \& Orecchioni, A. (1995). Optimization and in vitro stability of legumin nanoparticles obtained by a coacervation method. International Journal of Pharmaceutics, 126(1), 103-109.

Iyer, R., \& Tomar, S. (2009). Folate: A functional food constituent. Journal of Food Science, 74(9), R114-R122.

Kolb, A. F., \& Petrie, L. (2013). Folate deficiency enhances the inflammatory response of macrophages. Molecular Immunology, 54(2), 164-172.

Kuang, S. S., Oliveira, J. C., \& Crean, A. M. (2010). Microencapsulation as a tool for incorporating bioactive ingredients into food. Critical Reviews in Food Science and Nutrition, 50(10), 951-968.

Lamers, Y. (2011). Folate recommendations for pregnancy, lactation, and infancy. Annals of Nutrition \& Metabolism, 59(1), 32-37.

Madziva, H., Kailasapathy, K., \& Phillips, M. (2006). Evaluation of alginate-pectin capsules in cheddar cheese as a food carrier for the delivery of folic acid. LWTFood Science and Technology, 39(2), 146-151.

Mason, J. B., Shoda, R., Haskell, M., Selhub, J., \& Rosenberg, I. H. (1990). Carrier affinity as a mechanism for the $\mathrm{pH}$-dependence of folate transport in the small intestine. Biochimica Et Biophysica Acta (BBA)-Biomembranes, 1024(2), 331-335.

Nguyen, P., Boskovic, R., Yazdani, P., Kapur, B., Vandenberghe, H., \& Koren, G. (2008). Comparing folic acid pharmacokinetics among women of childbearing age: Single dose ingestion of 1.1 versus 5 MG folic acid. The Canadian Journal of Clinical Pharmacology = Journal Canadien De Pharmacologie Clinique, 15(2), e314-22.

Off, M. K., Steindal, A. E., Porojnicu, A. C., Juzeniene, A., Vorobey, A., Johnsson, A., \& Moan, J. (2005). Ultraviolet photodegradation of folic acid. Journal of Photochemistry and Photobiology B: Biology, 80(1), 47-55.

Ohrvik, V. E., \& Witthoft, C. M. (2011). Human folate bioavailability. Nutrients, 3(4), 475-490. 
O'Leary, K., \& Sheehy, P. (2001). Effects of preparation and cooking of folic acidfortified foods on the availability of folic acid in a folate depletion/repletion rat model. Journal of Agricultural and Food Chemistry, 49(9), 4508-4512.

Pan, X., Mu, M., Hu, B., Yao, P., \& Jiang, M. (2006). Micellization of casein-graft-dextran copolymer prepared through maillard reaction. Biopolymers, 81(1), 29-38.

Quintanilla-Carvajal, M. X., Camacho-Díaz, B. H., Meraz-Torres, L. S., Chanona-Pérez, J. J., Alamilla-Beltrán, L., Jimenéz-Aparicio, A., \& Gutiérrez-López, G. F. (2010). Nanoencapsulation: A new trend in food engineering processing. Food Engineering Reviews, 2(1), 39-50.

Reza Mozafari, M., Johnson, C., Hatziantoniou, S., \& Demetzos, C. (2008). Nanoliposomes and their applications in food nanotechnology. Journal of Liposome Research, 18(4), 309-327.

Russell, R. M., Golner, B. B., Krasinski, S. D., Sadowski, J. A., Suter, P. M., \& Braun, C. L. (1988). Effect of antacid and $\mathrm{H} 2$ receptor antagonists on the intestinal absorption of folic acid. The Journal of Laboratory and Clinical Medicine, 112(4), 458-463.

Schmitz, J. C., Stuart, R. K., \& Priest, D. G. (1994). Disposition of folic acid and its metabolites: A comparison with leucovorin. Clinical Pharmacology \& Therapeutics, 55(5), 501-508.

Semo, E., Kesselman, E., Danino, D., \& Livney, Y. D. (2007). Casein micelle as a natural nano-capsular vehicle for nutraceuticals. Food Hydrocolloids, 21(5), 936-942.

Shapira, A., Davidson, I., Avni, N., Assaraf, Y. G., \& Livney, Y. D. (2012). B-casein nanoparticle-based oral drug delivery system for potential treatment of gastric carcinoma: Stability, target-activated release and cytotoxicity. European Journal of Pharmaceutics and Biopharmaceutics, 80(2), 298-305.

Sierra, I., \& Vidal-Valverde, C. (1997). A simple method to determine free and glycosylated vitamin B6 in legumes. Journal of Liquid Chromatography \& Related Technologies, 20(6), 957-969.

Silva, H. D., Cerqueira, M. Â, \& Vicente, A. A. (2012). Nanoemulsions for food applications: Development and characterization. Food and Bioprocess Technology, 5(3), 854-867.

Teng, Z., Luo, Y., \& Wang, Q. (2012). Nanoparticles synthesized from soy protein: Preparation, characterization, and application for nutraceutical encapsulation. Journal of Agricultural and Food Chemistry, 60(10), 2712-2720.

Udabage, P., McKinnon, I. R., \& Augustin, M. A. (2003). The use of sedimentation field flow fractionation and photon correlation spectroscopy in the characterization of casein micelles. Journal of Dairy Research, 70(04), 453-459.

Walstra, P. (1999). Casein sub-micelles: Do they exist? International Dairy Journal, 9(3), 189-192.

Weiss, J., Decker, E. A., McClements, D. J., Kristbergsson, K., Helgason, T., \& Awad, T. (2008). Solid lipid nanoparticles as delivery systems for bioactive food components. Food Biophysics, 3(2), 146-154. 
Ye, A., Flanagan, J., \& Singh, H. (2006). Formation of stable nanoparticles via electrostatic complexation between sodium caseinate and gum arabic. Biopolymers, 82(2), 121-133.

Zhang, J., Liu, Y., Liu, X., Li, Y., Yin, X., Subirade, M., . . Liang, L. (2014). The folic acid/ $\beta$ casein complex: Characteristics and physicochemical implications. Food Research International, 57(0), 162-167.

Zhen, X., Wang, X., Xie, C., Wu, W., \& Jiang, X. (2013). Cellular uptake, antitumor response and tumor penetration of cisplatin-loaded milk protein nanoparticles. Biomaterials, 34(4), 1372-1382.

Zhong, Q., Tian, H., \& Zivanovic, S. (2009). Encapsulation of fish oil in solid zein particles by liquid-liquid dispersion. Journal of Food Processing and Preservation, $33(2), 255-270$.

Zimet, P., Rosenberg, D., \& Livney, Y. D. (2011). Re-assembled casein micelles and casein nanoparticles as nano-vehicles for $\omega-3$ polyunsaturated fatty acids. Food Hydrocolloids, 25(5), 1270-1276. 


\section{Figure captions}

Figure 1. Scanning electron microscopy (SEM) of folic acid-loaded casein nanoparticles. a) Nanoparticles prepared in normal conditions without using a high pressure procedure (FA-NP-C); b) Nanoparticles prepared with a hydrodynamic pressure treatment of $100 \mathrm{MPa} / 5 \mathrm{~min}$ (FA-NP-C-P1); c) Nanoparticles prepared with a hydrodynamic pressure treatment of $400 \mathrm{MPa} / 5 \mathrm{~min}$ (FA-NP-C-P3).

Figure 2. In vitro release studies of folic acid from casein nanoparticles after its incubation in simulated gastric fluid (SGF) during the first 2 hours and simulated intestinal fluid (SIF) (2-24h). A) Nanoparticles without high pressure treatment (FA-NPC), B) Nanoparticles treated with high pressure (FA-NP-C-P3). Data expressed as mean $\pm \operatorname{SD}(n=4)$.

Figure 3. Folic acid concentration vs time after a single intravenous administration of folic acid solution (dose $1 \mathrm{mg} / \mathrm{kg}$ ). Data expressed as mean $\pm S D,(n=6)$.

Figure 4. Folic acid concentration vs time after a single oral administration of the different formulations at dose of $1 \mathrm{mg} / \mathrm{kg}$. i) PBS ( $\mathbf{(})$, ii) Folic acid (FA) solution (FA sol, $\bullet$ ), iii) FA-loaded casein nanoparticles (FA-NP-C, $\bullet$ ), iv) FA-loaded casein nanoparticles treated by high hydrodynamic pressure (FA-NP-C- $\left.P_{3}, \nabla\right)$. Data expressed (mean \pm SD, $\mathrm{n}=6)$

* $p<0.05$ FA-NP-C vs FA solution. $U$ de Mann Whitney test.

$\mp p<0.05$ FA-NP-C-P 3 vs FA solution. U de Mann Whitney test. 


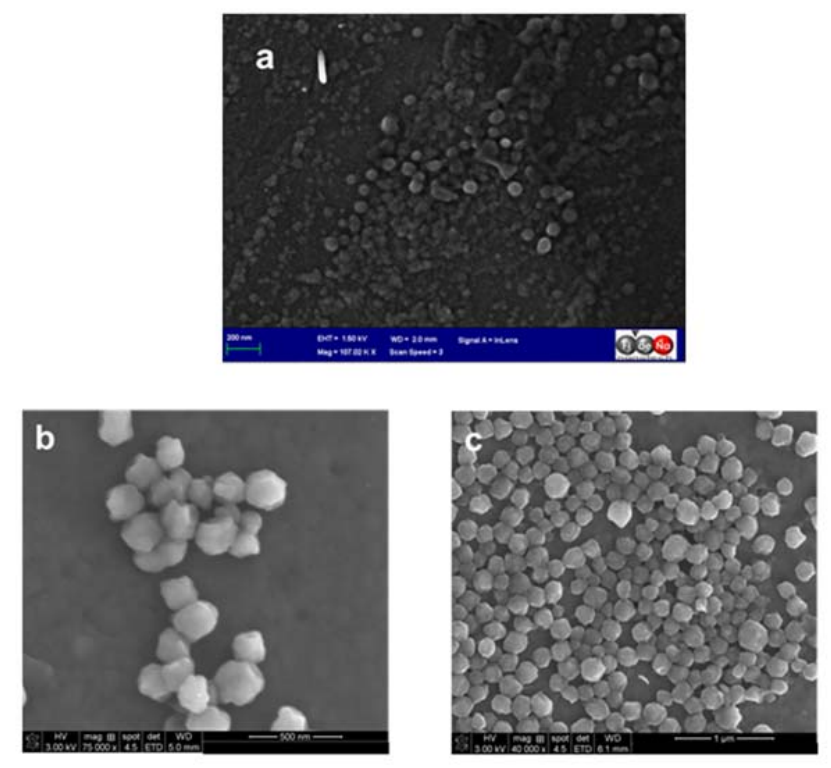



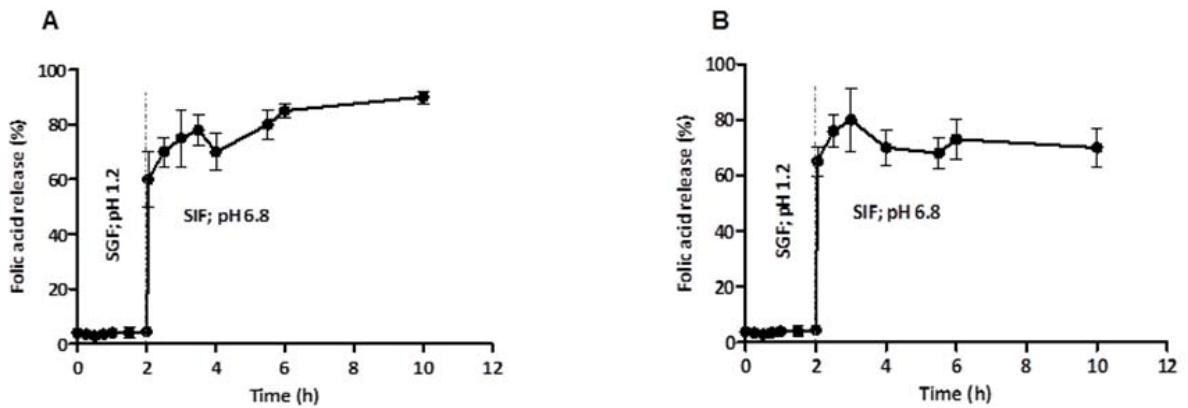


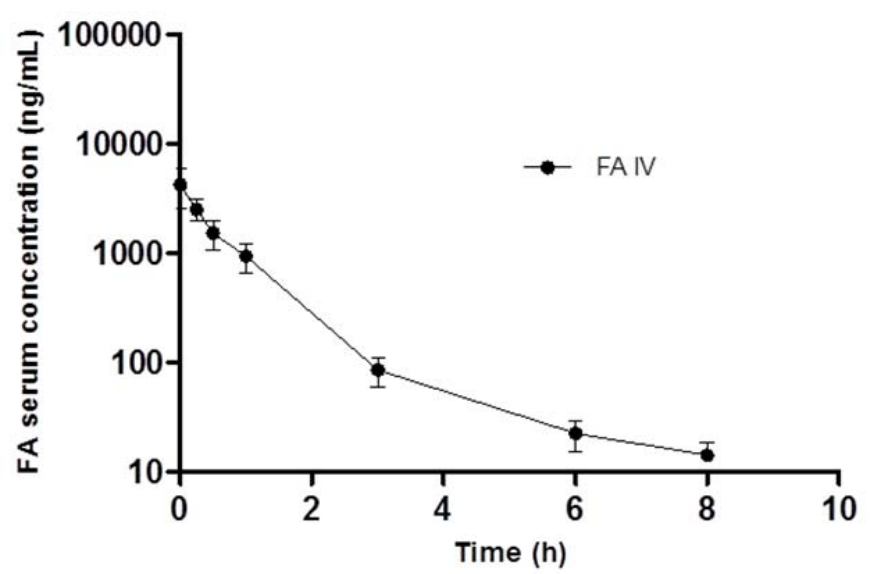




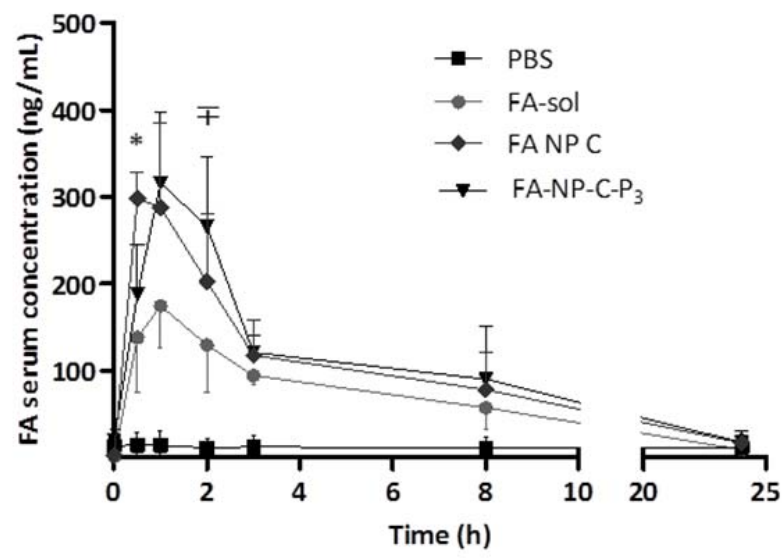




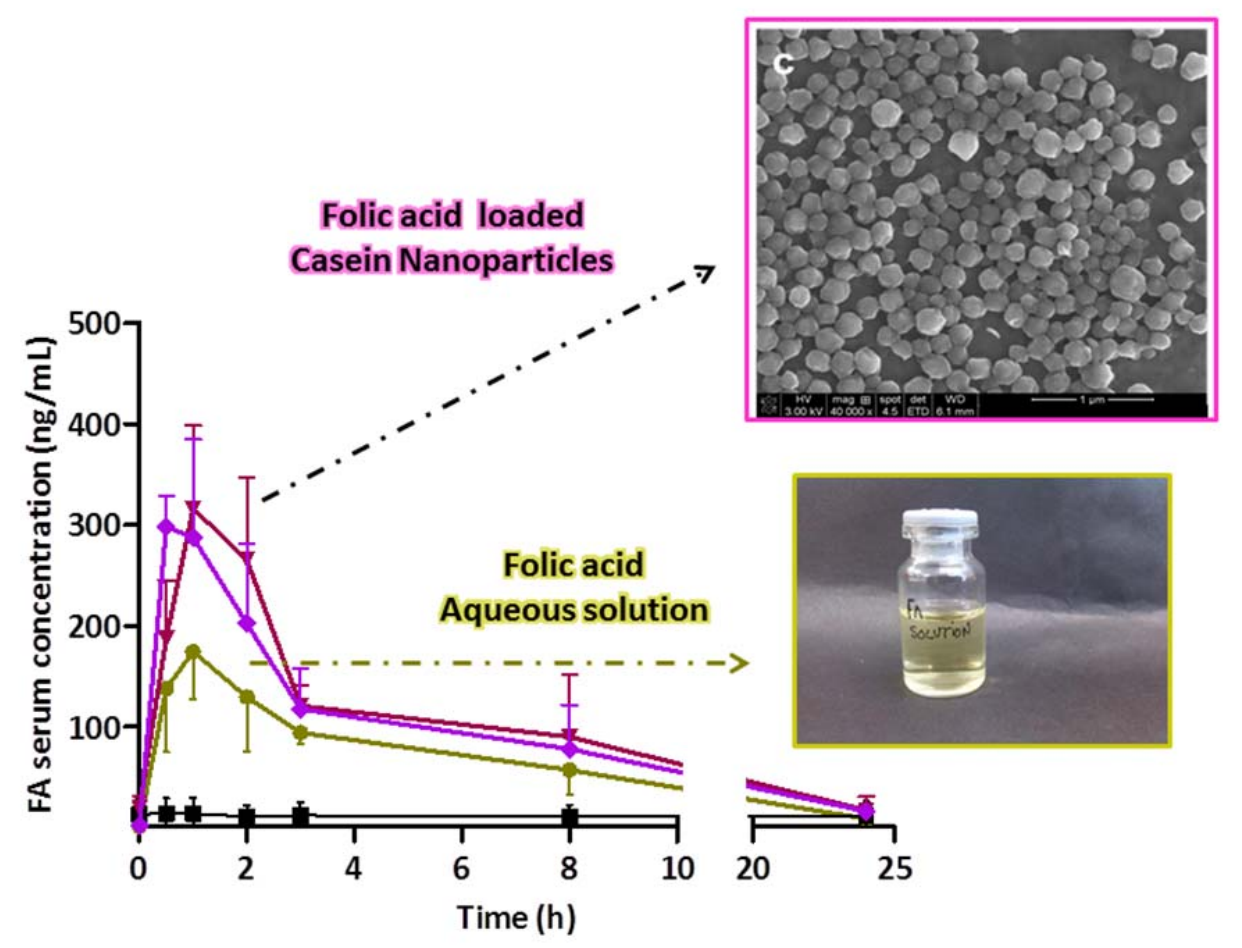


Table 1. Folic Acid HPLC gradient (A: phosphoric acid 33mM, B: acetonitrile).

\begin{tabular}{ccc}
\hline $\begin{array}{c}\text { Time } \\
(\mathbf{m i n})\end{array}$ & A (\%) & B (\%) \\
\hline 0 & 95 & 5 \\
8 & 95 & 5 \\
33 & 82.5 & 17.5 \\
45 & 95 & 5 \\
\hline
\end{tabular}

Table 2. Physico-chemical characteristics of casein nanoparticles prepared in the presence of either lysine or arginine as stabilizing agents at an amino acid/protein ratio of 0.12 before the drying step. Data expressed as mean $\pm S D, n=6$. PDI: polydispersity index.

\begin{tabular}{lccccc}
\hline & $\begin{array}{c}\text { Stabilising } \\
\text { agent }\end{array}$ & $\begin{array}{c}\text { Mean size } \\
(\mathbf{n m})\end{array}$ & PDI & $\begin{array}{c}\text { Zeta } \\
\text { potential } \\
(\mathbf{m V})\end{array}$ & Yield (\%) \\
\hline NP-1 & None & $154 \pm 30$ & $0.24 \pm 0.04$ & $-17.6 \pm 0.3$ & $97 \pm 5$ \\
NP-2 & Lysine & $128 \pm 4$ & $0.18 \pm 0.01$ & $-14.0 \pm 0.5$ & $95 \pm 3$ \\
NP-3 & Arginine & $135 \pm 2$ & $0.17 \pm 0.01$ & $-14.5 \pm 0.6$ & $97 \pm 1$ \\
\hline
\end{tabular}

Table 3. Effect of the drying step with a Spray-drying apparatus on the physicochemical properties of casein nanoparticles. Data expressed as mean $\pm S D, n=3$. PDI: polydispersity index.

\begin{tabular}{lcccc}
\hline & $\begin{array}{c}\text { Stabilizing } \\
\text { agent }\end{array}$ & $\begin{array}{c}\text { Mean } \\
\text { size }(\mathbf{n m})\end{array}$ & PDI & $\begin{array}{c}\text { Zeta potential } \\
(\mathbf{m V})\end{array}$ \\
\hline NP-1 & None & $305 \pm 56$ & $0.45 \pm 0.02$ & $-9.8 \pm 0.2$ \\
NP-2 & Lysine & $170 \pm 4$ & $0.25 \pm 0.02$ & $-11.9 \pm 0.9$ \\
NP-3 & Arginine & $184 \pm 2$ & $0.25 \pm 0.01$ & $-9.4 \pm 0.2$ \\
\hline
\end{tabular}


Table 4. Physico-chemical characteristics of folic acid-loaded casein nanoparticles. Data expressed as mean \pm SD $(n=4)$.

\begin{tabular}{|c|c|c|c|c|c|}
\hline & $\begin{array}{c}\text { High } \\
\text { pressure } \\
\text { treatment }\end{array}$ & $\begin{array}{l}\text { Size } \\
(\mathrm{nm})\end{array}$ & PDI & $\begin{array}{c}\text { Zeta } \\
\text { potential } \\
(\mathrm{mV})\end{array}$ & $\begin{array}{c}\text { FA loading } \\
(\mu \mathrm{g} / \mathrm{mg} \\
\mathrm{NP})\end{array}$ \\
\hline NP-C & NA & $170 \pm 4$ & $0.25 \pm 0.02$ & $-11.9 \pm 0.9$ & \\
\hline FA-NP-C & NA & $157 \pm 5$ & $0.17 \pm 0.01$ & $-17.2 \pm 1.2$ & $24 \pm 1$ \\
\hline FA-NP-C-P 1 & $\begin{array}{c}100 \mathrm{MPa} / \\
5 \mathrm{~min}\end{array}$ & $144 \pm 3$ & $0.13 \pm 0.01$ & $-13.6 \pm 0.2$ & $25 \pm 5$ \\
\hline FA-NP-C-P ${ }_{2}$ & $\begin{array}{c}200 \mathrm{MPa} / \\
5 \mathrm{~min}\end{array}$ & $139 \pm 1$ & $0.22 \pm 0.02$ & $-13.2 \pm 0.5$ & $23 \pm 1$ \\
\hline FA-NP-C-P 3 & $\begin{array}{c}400 \mathrm{MPa} / \\
5 \mathrm{~min}\end{array}$ & $134 \pm 3$ & $0.14 \pm 0.01$ & $-14.1 \pm 2.3$ & $25 \pm 2$ \\
\hline FA-NP-C-P 4 & $\begin{array}{c}600 \mathrm{MPa} / \\
5 \mathrm{~min}\end{array}$ & $111 \pm 2$ & $0.15 \pm 0.01$ & $-12.8 \pm 0.4$ & $31 \pm 3$ \\
\hline
\end{tabular}


Table 5. Pharmacokinetic parameters estimated after a single dose of $1 \mathrm{mg} / \mathrm{kg}$ body weight of folic acid formulated in nanoparticles or in a solution, either orally or intravenously administered. FA: folic acid; FA sol: folic acid aqueous solution; FA-NP-C: FA-loaded casein nanoparticles; FA-NP-C-P ${ }_{3}$ : FA-loaded casein nanoparticles treated by high hydrodynamic pressure. $(n=6)$.

\begin{tabular}{|c|c|c|c|c|c|c|c|c|c|}
\hline & Route & $\begin{array}{c}C \max \\
(\mu \mathrm{g} / \mathrm{mL})\end{array}$ & $\begin{array}{c}\max \\
\text { (h) }\end{array}$ & $\begin{array}{c}\text { AUC } \\
(\mu \mathrm{gh} / \mathrm{mL})\end{array}$ & $\begin{array}{l}T 1 / 2 \\
\text { (h) }\end{array}$ & $\begin{array}{c}\mathrm{Cl} \\
(\mathrm{L} / \mathrm{h})\end{array}$ & $\begin{array}{l}\text { Vd } \\
\text { (L) }\end{array}$ & $\begin{array}{c}\text { MRT } \\
\text { (h) }\end{array}$ & $\begin{array}{l}\mathrm{Fr} \\
\text { (\%) }\end{array}$ \\
\hline PBS & p.o & - & - & - & - & - & & - & - \\
\hline FA i.v. & p.iv & $5.5 \pm 2.7^{* *}$ & 0 & $3.7 \pm 0.4^{* *}$ & $1.2 \pm 0.6$ & $0.06 \pm 0.01$ & $0.10 \pm 0.05$ & $0.9 \pm 0.2^{* *}$ & $100^{* *}$ \\
\hline FA sol & p.o. & $0.2 \pm 0.0$ & $1.0 \pm 0.6$ & $1.3 \pm 0.3$ & $5.9 \pm 1.9$ & $0.06 \pm 0.02$ & $0.44 \pm 0.07$ & $5.7 \pm 1.6$ & 35 \\
\hline FA-NP-C & p.o. & $0.3 \pm 0.1$ & $1.2 \pm 0.4$ & $2.1 \pm 0.6^{*}$ & $5.8 \pm 2.1$ & $0.05 \pm 0.02$ & $0.42 \pm 0.10$ & $5.8 \pm 1.2$ & $52^{*}$ \\
\hline FA-NP-C 3 & p.o. & $0.3 \pm 0.0^{*}$ & $0.8 \pm 0.3$ & $2.2 \pm 0.4^{*}$ & $7.3 \pm 2.3$ & $0.05 \pm 0.01$ & $0.54 \pm 0.24$ & $6.1 \pm 0.9$ & $53^{*}$ \\
\hline
\end{tabular}

AUC: area under the curve concentration-time from time 0 to $\infty, \mathrm{C}_{\max }$ : peak plasma concentration; $\mathrm{T}_{\max }$ : time to peak plasma concentration; $\mathrm{t}_{1 / 2 \mathrm{z}}$ : half-life of the terminal phase; $\mathrm{Cl}$ : clearance; MRT: mean residence time; Fr: relative oral bioavailability.

* $p<0.05$ vs FA solution. $U$ de Mann Whitney Test.

** $p<0.01$ vs FA solution. $U$ de Mann Whitney test. 


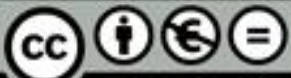

BY NC ND Esta obra está bajo una licencia de Creative Commons Reconocimiento-

NoComercial-SinObraDerivada 4.0 Internacional. 